\title{
PERWUJUDAN RANCANG BENTUK GEDUNG DENGAN KONSEP HYBRID PADA KANTOR RUKUN WARGA 015 KELURAHAN PLUIT, KECAMATAN PENJARINGAN
}

\author{
Rudy Trisno ${ }^{1}$, Fermanto Lianto ${ }^{1}$, James Rilatupa ${ }^{1}$ \\ ${ }^{1}$ Jurusan Teknik Arsitektur, Universitas Tarumanagara Jakarta \\ Email: rudyt@ft.untar.ac.id \\ Email: fermantol@ft.untar.ac.id \\ Email: jedrilatupa@gmail.com
}

\begin{abstract}
ABSTRAK
Kemajuan teknologi digital menyebabkan manusia bersifat individualisme khususnya golongan menengah ke atas, maka diperlukan suatu wadah untuk warga berkumpul. Universitas Tarumanagara dengan kegiatan di bidang pengabdian pada masyarakat bersedia membantu mewujudkan rancangan bentuk gedung dengan tidak menyimpang dari isu tadi. Pada pembuatan rancangan perlu dipikirkan bagaimana wadah ini menjadi aktif dan bermanfaat bagi warga dan juga pengurus warga. Metode yang digunakan adalah: Pertama, mengumpulkan kebutuhan ruang dari pemangku jabatan, kemudian mengkaji konsep Hybrid dan Symbiosis pada bangunannya; Kedua, konsep ini dapat diaplikasikan pada bangunan yang dirancangan; Ketiga, setelah itu dibuatkan gambar prarencanan dan pelaksanaannya. Temuan dalam penelitian ini adalah mengekspresikan bentuk sesuai dengan konsep hybrid untuk dilaksanakan di lapangan. Sehingga rancangan ini dapat digunakan pada kantor-kantor $R W$ lainnya, khususnya daerah Pluit.
\end{abstract}

Kata Kunci: Metode perancangan, Kantor Rukun Warga (RW), Konsep Symbiosis-Hybrid, PKM.

\section{PENDAhUluan}

Kemajuan teknologi khusus teknologi digital membuat manusia cenderung bersikap individualisme, hal ini juga dipengaruhi lokasi lingkungan khusus lingkungan perumahan menengah ke atas (Dalyono, 2010). Untuk menanggulangi masalah ini maka diperlukan suatu wadah untuk mengembalikan fungsi dari ruang bersama bagi sesama warga untuk berkumpul dan saling berbagi.

Berdasarkan hal di atas maka salah satu peran Universitas Tarumangara di bidang pengabdian pada masyarakat untuk membantu membuatkan rancangan agar tidak menyimpang dari rencana semula, adapun tahapan pertama adalah menanyakan kebutuhan ruang apa saja yang diperlukan oleh warganya; kedua, mengolah data yang ada untuk disusun program ruang; ketiga, program ruang yang tersusun untuk diekspresikan ke bentuk bangunan; keempat, membuat gambar perancangan dan gambar pelaksanaan (Detailed Engineering Drawing).

Permasalahan manusia cenderung bersikap individualisme dalam lingkungan, karena tidak adanya wadah untuk berkumpul yang nyaman dan saling menguntungkan bagi warganya. Permasalahan ini dapat diatasi dengan suatu wadah yang dapat saling menguntungkan antara warga satu dengan warga lainnya, selain itu juga adanya suatu ruangan yang tidak hanya berlaku untuk satu fungsi saja, misalnya ruang rapat atau ruang olah raga hanya digunakan satu kegiatan saja perlu dipikirkan kegiatan yang dapat digunakan untuk kegiatan lainnya dan juga menguntungkan bagi warganya 
Manfaat dari penelitian ini adalah; pertama, bangunan ini merupakan solusi dari permasalahan individualisme bagi warga dalam lingkungan kompleks perumahan; kedua, adanya hubungan yang harmonis antara masing-masing warga dan juga pemangku kepentingan; ketiga, bangunan ini dapat dijadikan contoh model untuk bangunan kantor RW lainnya, khususnya di lingkungan Pluit dan sekitarnya

\section{KAJIAN PUSTAKA DAN METODE}

Di antara berbagai kesempatan yang berputar pada setiap sudut alam semesta ini, kita berada pada dunia ini, seolah-olah terperangkap dalam raga yang memproyeksikan jiwanya secara nyata. Manusia dianugerahi dengan akal budi yang dapat menjadikan dan juga mampu untuk memproses hal-hal yang terjadi di sekitarnya; di mana hal-hal tersebut juga akan mempengaruhi jalan hidupnya (Cassirer, 1965, hal.72).

Hal ini terlihat dari salah satu pandangan Heidegger di mana manusia memiliki pemahaman kompleks yang mendalam terhadap dirinya, namun hal tersebut akan terlihat melalui caranya merespon benda di sekelilingnya, situasi yang terjadi, dan hubungan timbal balik dengan orang lain (Meyer, 2013, hal.. 71 dan Escudero, 2014).

Berdasarkan pandangan Cassier dan Meyer dalam Heidegger dapat disimpulkan bahwa sikap individualisme dapat diatasi dengan suatu wadah yang dapat memberikan hubungan timbal balik dengan orang lain. Dalam arsitektur masalah spatial merupakan suatu wadah yang dapat melingkupi hubungan timbal balik dan saling menguntungkan, baik secara eksterior maupun interior yang akan mempengaruhi kualitas ruang tersebut, apakah ruang ini memberikan ruang yang bersifat ruang positif atau ruang negatif (Ashiara, 1971), hal ini berarti menunjukan adanya kwalitas ruang, sebagai perwujudan wadah spatial yang akan mempengaruhi fungsi pada kegiatannya.

Pengertian Hybrid (Jenkcs, 1978), konsep Hybrid merupakan salah satu metode perancangan dalam sebuah karya arsitektur yang muncul di era Post Modern. Secara etimologis Hybrid merupakan penggabungan beberapa aspek yang berbeda (binari oposisi), tentunya dalam bidang arsitektural. Berikut ini akan diuraikan pengertian Hybrid berdasarkan maknanya.

Pertama, yaitu dua hal atau lebih yang digabung untuk membentuk satu kesatuan dan kedua adalah perkawinan/keturunan dari dua jenis yang berbeda baik varietas, ras atau spesies yang berbeda. Dalam analisis bahwa perbedaan varietas bisa saja masih menjadi satu spesies, perbedaan ras bisa saja masih dalam satu spesies sebaliknya beda spesies bisa saja masih dalam satu ras dan varietas. Dari pengertian di atas dapat disimpulkan bahwa Hybrid merupakan penggabungan dari sesuatu yang memiliki perbedaan atau hasil persilangan antara sesuatu yang berbeda dengan adanya dominasi dari salah satu kutub yang berbeda.

Konsep Hybrid merupakan percampuran atau keturunan dari dua hal yang bertentangan (binari oposisi). Sehingga dalam terjadi dominasi oleh salah satu kutub yang bertentangan. Dalam pengertian Hybrid terbagi atas persilangan, percampuran dan penggabungan. Kekayaan makna 
dalam Hybrid diciptakan dengan melakukan manipulasi kode-kode referensi yang telah mapan dan memadukan atau menggabungkan kode-kode referensi yang telah dimanipulasi tersebut dalam desain

Sedangkan konsep Symbiosis (Kurokawa, 1994) merupakan perpaduan dua hal yang bertentangan (binari oposisi) dalam suatu entitas baru yang di dalamnya unsur-unsur tersebut masih independen. Dalam Symbiosis terdapat pembagian zona yang di dalamnya merupakan zona suci dan zona perantara. Zona suci merupakan karakter atau ciri khas dari sebuah objek atau budaya, sedangkan zona antara merupakan zona atau ruang yang menjadi perantara atau penghubung dari dua objek yang berbeda dengan masing-masing zona suci mereka yang dimodifikasi atau manipulasi sehingga pada ruang antara ini benar-benar mampu menggambarkan keadaan pada kedua objek yang bertentangan tersebut.

Dari hasil analisis pada bagian sebelumnya mengenai konsep Hybrid dan Symbiosis dalam arsitektur, maka penulis menarik sebuah kesimpulan bahwa konsep Hybrid yang dikemukakan oleh Charles Jenkcs dan Symbiosis oleh Kisho Kurokawa bahwa kedua konsep penggabungan ini adalah sama. Dengan melihat kesamaan yang dimiliki keduanya.

Dalam perancangan arsitektur bangunan dengan mengkaitkan Symbiosis (Kurokawa, 1994) dan Hybrid (Jenkcs, 1978), adalah suatu cara yang mengabungkan fungsi kegiatan bangunan yang dirancang dan juga merupakan salah satu jawaban dari permasalahan isu utama yaitu individualisme bagi warga dalam lingkungannya (binary oposisi). Karena dalam konsep Kurokawa (1994) mencoba menggabungkan hubungan yang saling menguntungkan baik pada manusia dan juga pada kegiatan dari fungsi bangunannya, sehingga bangunan ini akan memberikan nilai tambahan pada lingkungannya. Sedangkan Per et al (2011) melanjutkan konsep Hybrid dari Charles Jenkcs dan juga mengembangan konsep Symbiosis dari Kurokawa (1994), dalam uraiannya mengatakan bahwa, pemanfaatan ruang sebaiknya tidak hanya digunakan satu kegiatan saja tapi dapat di-Hybrid-kan dengan kegiatan lain sehingga diharapkan kegiatan ini saling mengisi (Per et al, 2011, hal. 9).

Ekspresi bentuk yang dirancang pada bangunan dengan konsep Hybrid ini menggunakan teknologi modern, teknologi modern dapat memperlihatkan spirit zaman (Jodidio, 2015). Penggunaan material bahan dari aluminium, rangka baja, plafond gypsum, dan kusen aluminium yang digunakan dalam perancangan bangunan ini, merupakan jalan keluar dari masalah rayap pada bangunan eksistingnya sedangkan penggunaan CCTV, koneksi internet untuk keamanan, dan juga untuk berkumpul warga yang ingin menggunakan koneksi internet. Perancangan dengan menggunakan bahan-bahan dari besi, alumunim, komputer dan juga teknologi komunikasi, merupakan suatu pencerminan gaya modern (Nose, 2000, hal. 6-7).

Jadi metode untuk mengekspresikan bentuk kasus studi berdasarkan kajian teoritis adalah; pertama, mengumpulkan data yang diperlukan oleh warga berdasarkan wawancara dari seluruh pemangku jabatan dan juga ketua RW; kedua setelah diinventariskan kebutuhan ruang dicoba dengan mengkaitkan mana ruang yang dapat dikelompokkan dan dikaitkan dengan pendekatan Kurokawa (1994) dan Per et al (2011); ketiga, mengekspresikan bentuk bangunan sesuai dengan konsep 
Hybrid; keempat, membuat gambar perencanaan dan gambar pelaksanaan (Detailed Enginnering Drawing).

\section{HASIL DAN ANALISIS}

Dalam menelaah hasil dan analisis maka dilakukan tahap sebagai berikut ini;

Pertama, mengumpulkan data kebutuhan ruang yang diwakili oleh pemangku jabatan dan ketua RW 015, kemudian disusun kebutuhan Ruang Kantor RW yang meliputi; a). Kantor RW; b). Kantor Administrasi; c). Ruang Rapat Besar; d). Ruang Rapat Kecil; e). Tempat Tidur untuk keamanan sebanyak 10 orang; f). Locker untuk 10 orang; g). Gudang; h). Pantry; i). Toilet untuk rapat atau kantor. Oleh karena bangunan eksisting sudah ada dan juga agar tidak menggunakan budget terlalu besar maka perancangan memaanfatkan potensi bangunan eksisting (Gambar 1). Pembangunan bangunan utama ini bersinergi dengan Lapangan Basket (Gambar 2), Taman (Gambar 3), Gazebo (Gambar 4) dan Toilet untuk aktivitas kegiatan ruang luar (Gambar 5).

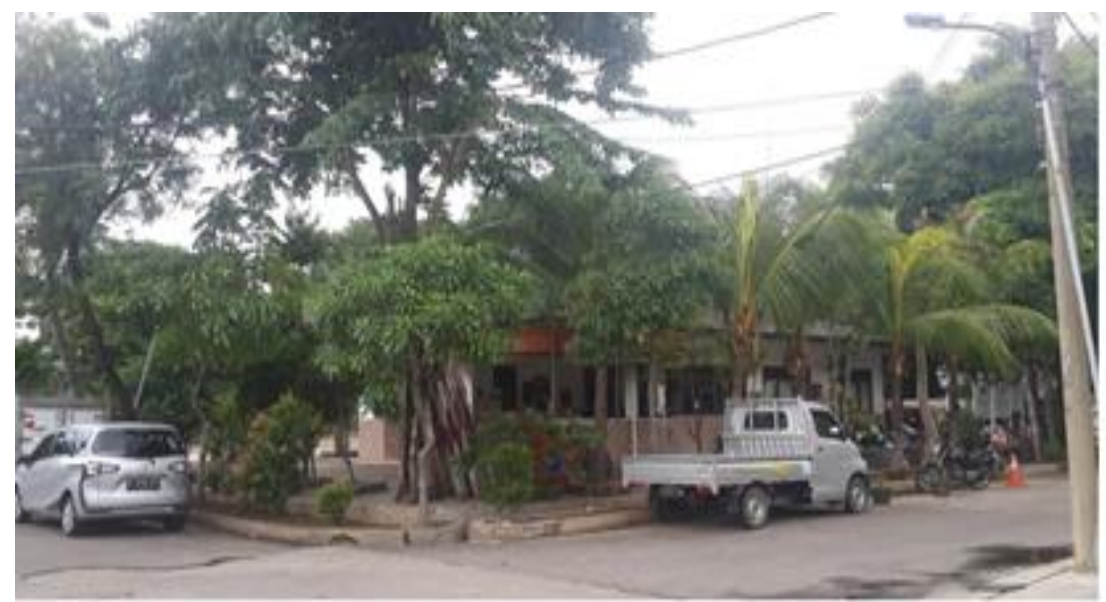

Gambar 1. Bangunan Kantor RW dan vegetasi eksisting dipertahankan.

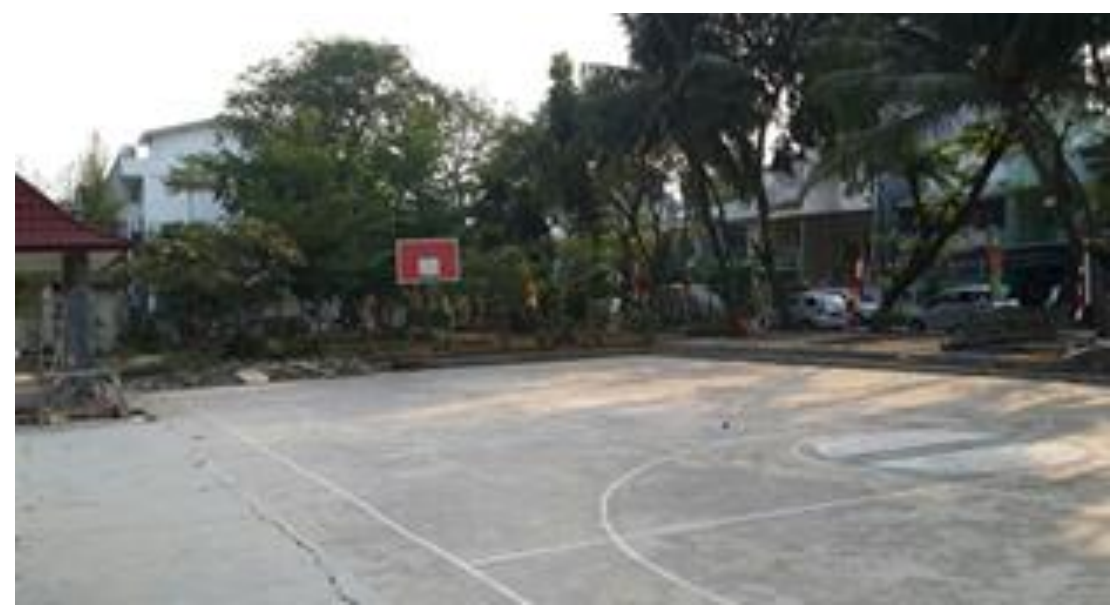

Gambar 2. Lapangan Basket 
Jurnal Bakti Masyarakat Indonesia

Vol. 2, No. 1, Mei 2019, Hal. 29-38

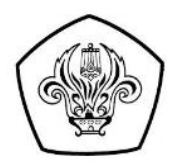

ISSN 2620-7710 (Versi Cetak) ISSN 2621-0398 (Versi Elektronik)

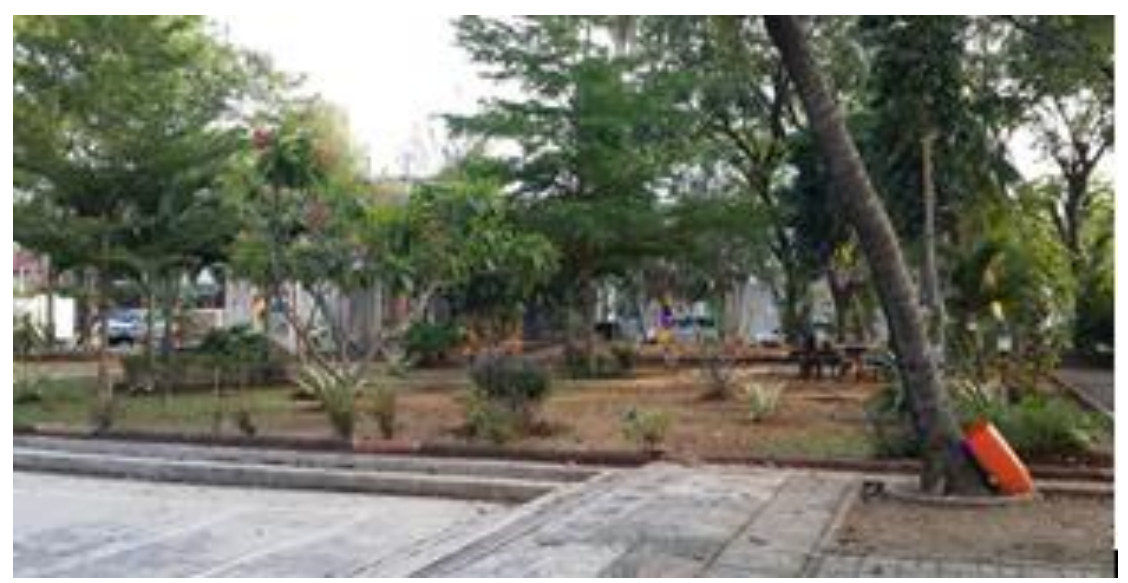

Gambar 3. Taman

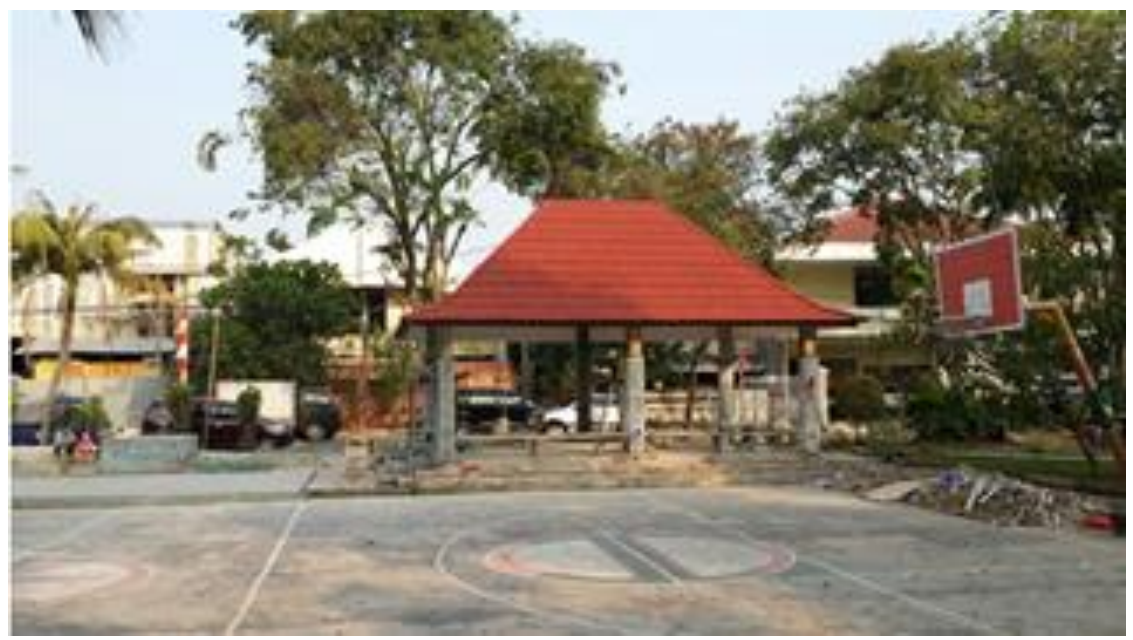

Gambar 4. Gazebo

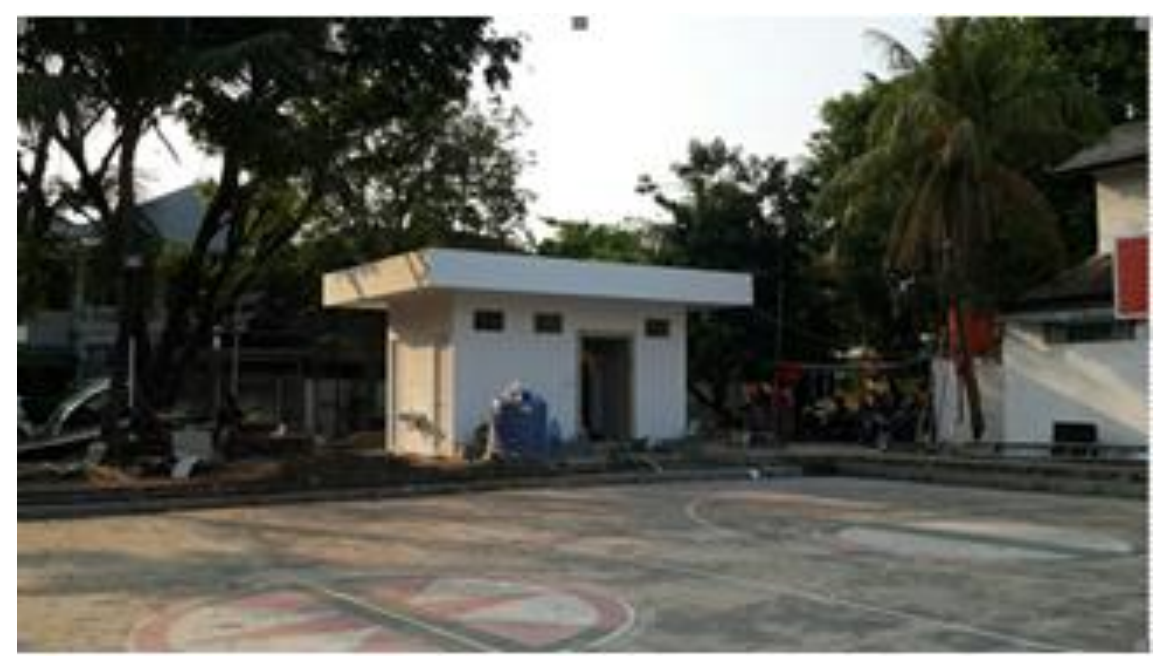

Gambar 5. Toilet kegiatan di luar 
Kedua, kebutuhan ruang yang ada dicoba dan disusun kembali dengan cara menggabungkan fungsi ruang apakah bisa terjadinya suatu konsep Hybrid dikaitkan dengan kegiatan aktivitas warga sehingga terjadinya suatu Symbiosis pada kegiatan kantor RW. Sehingga diharapkan wadah spasial di dalamnya mengekspresikan bentuk arsitektur yang dapat digunakan tidak hanya untuk kegiatan kantor saja tapi dapat menghidupkan kantor tersebut dengan aktivitas warga. Ruang yang dapat dijadikan konsep Hybrid adalah Ruang Meeting besar dapat digunakan untuk kegiatan Ruang Serbaguna bagi warga, sedangkan Ruang Meeting Kecil dapat digunakan untuk Ruang Karaoke dan Ruang Pantry yang dapat digunakan untuk kegiatan ibu-ibu untuk kegiatan memasak baik di dalam ruang maupun di luar ruang. Pada saat ini lapangan basket digunakan untuk olah raga pagi, sedangkan gazebo selain digunakan untuk berkumpul warga dapat digunakan untuk senam di dalam gazebo jika hujan turun.

Ketiga, mengekspresikan bentuk bangunan sesuai dengan konsep Hybrid, dalam wujud ekspresi bangunan sebagai wadah spasial untuk melingkupi Ruang Meeting kecil untuk dapat dijadikan Ruang Karaoke, hal yang perlu diperhatikan pada Ruang Karaoke adalah permasalahan akustik suara dan fleksibilitas ruangan agar dapat memenuhi aktivitas tersebut. Untuk Ruang Meeting besar faktor fleksibilitas merupakan hal yang sangat utama, dalam penataan wadah spasial bangunan ini, perlu juga dipikirkan penataan furniture yang fleksibel. Ruang Pantry dapat melayani kegiatan di luar bangunan dan juga di dalam bangunan. Kantor RW dan kantor administrasi merupakan kantor yang hanya digunakan untuk pelayanan masyarakat, sehingga kegiatan ini tidak dapat di Hybrid kan. Ruang tinggal penjaga keamanan perlu diperhatikan faktor anthropometric, sehingga kapasitas ruang ini dapat terpenuhi.

Keempat, membuat gambar perencanaan dan gambar pelaksanaan (Detailed Engineering Drawing). Gambar perencanaan ini meliputi denah, tampak dan potongan. Setelah gambar itu dilanjutkan dengan gambar pelaksanaan yang membuat lebih rinci dari gambar perencanaan, agar ekspresi bentuk terpancar sesuai dengan wadah spasial yang dikonsepkan.

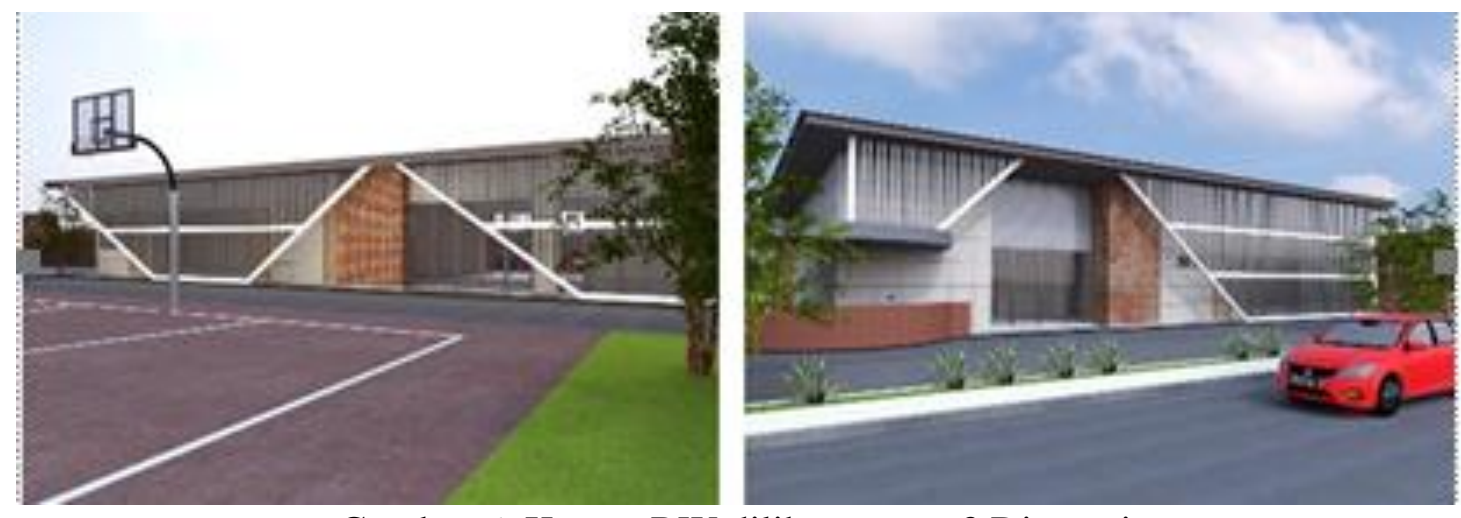

Gambar 6. Kantor RW dilihat secara 3 Dimensi. 


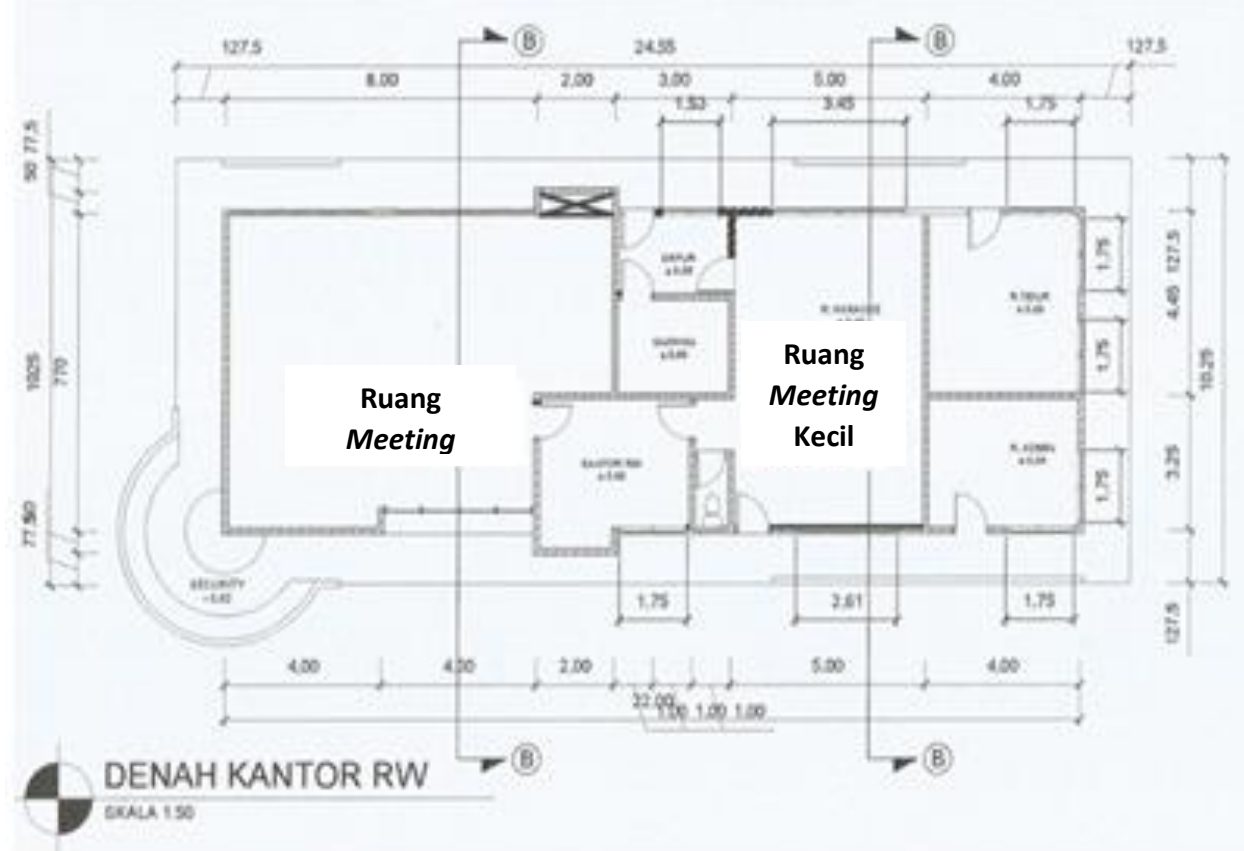

Gambar 7. Denah kantor RW rancangan satu lantai. 
Perwujudan Rancang Bentuk Gedung dengan Konsep

Rudy Trisno, et al Hybrid pada Kantor Rukun Warga 015 Kelurahan Pluit, Kecamatan Penjaringan
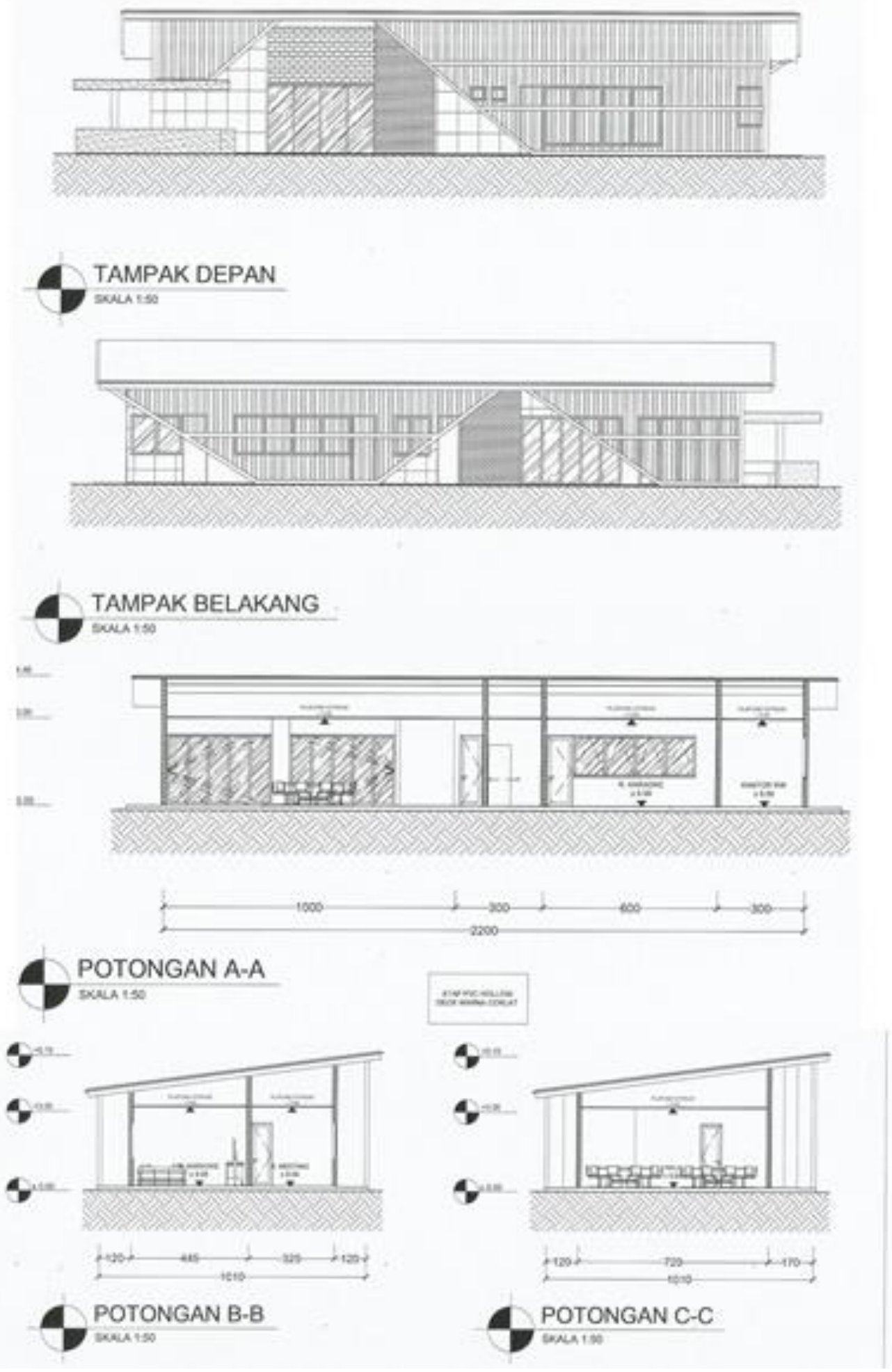

Gambar 8. Tampak dan Potongan kantor RW. 


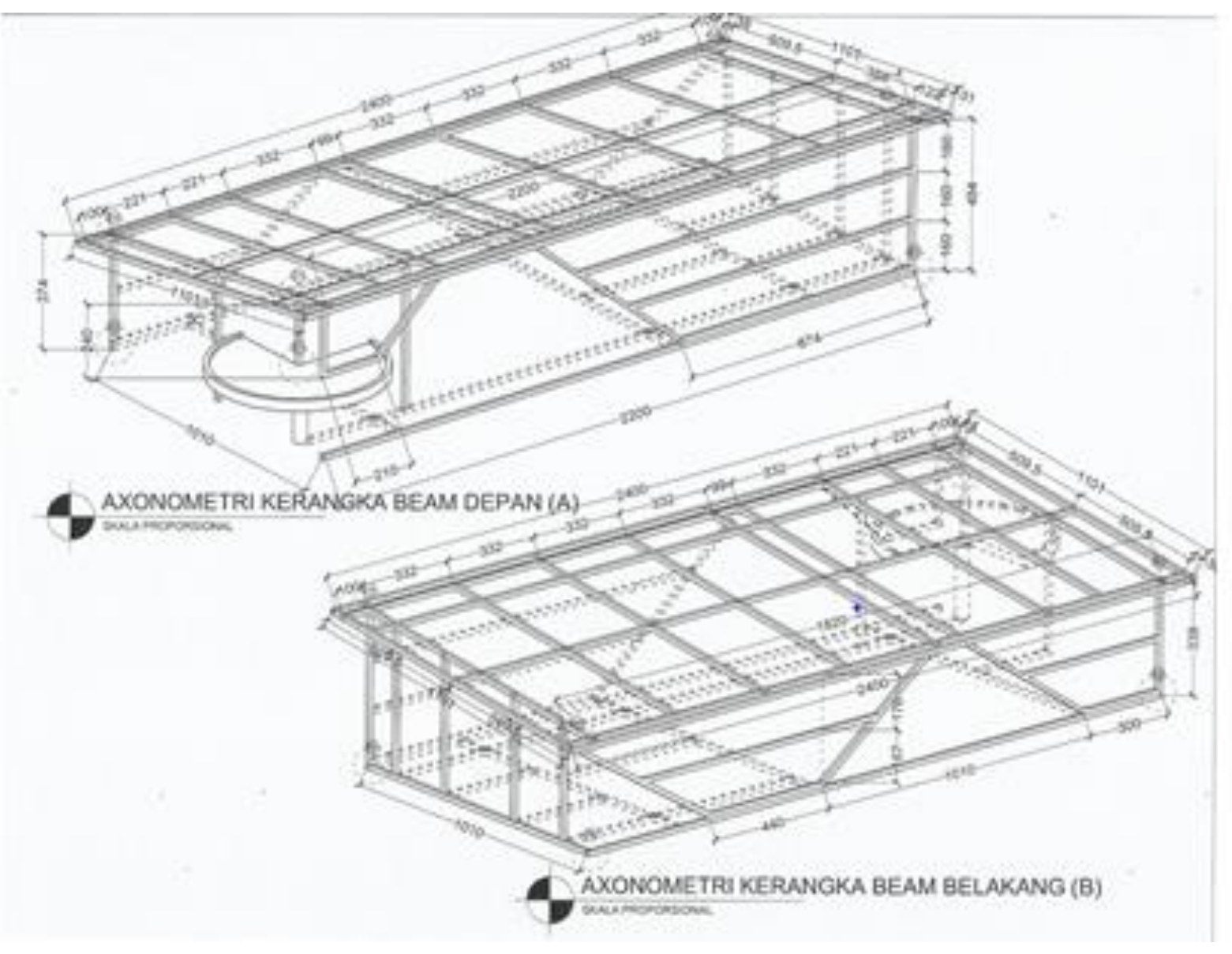

Gambar 9. Gambar pelaksanaan kantor RW.

\section{KESIMPULAN}

Dalam perancangan dengan konsep Hybrid perlu dijelaskan kepada pemangku jabatan, bahwa konsep ini digunakan tidak hanya untuk satu kegiatan saja, tapi dapat digunakan untuk kepentingan warga. Sehingga aktivitas bangunan ini dapat terjadi suatu kesinambungan yang merupakan perwujudan Symbiosis antara warga dengan kegiatan administrasi RW. Agar penyimpangan tidak terjadi di lapangan maka diperlukan suatu gambar pelaksanaan (Detailed Engineering Drawing) sebagai pedoman dan orientasi untuk pelaksanaan agar tidak terjadi banyak perubahan di lapangan, mengingat bahwa pembangunan kantor RW umumnya sering mendapat komentar dari orang-orang yang mendasari komentarnya berdasarkan pada pengalaman pribadi sehingga menyulitkan pekerjaan di lapangan. Hasil rancangan dari ekspresi bentuk ini, yang berdasarkan konsep Hybrid ini dapat juga digunakan untuk kantor-kantor RW yang lainnya khususnya di daerah kawasan Pluit.

Penelitian ini didasarkan pada metode konsep perancangan Hybrid, apakah hasil dari konsep ini setelah terbangun dapat menjawab permasalahan isu utama yaitu individualisme ?, untuk dapat melengkapinya sebaiknya setelah bangunan ini selesai harus ditriangulasi kepada warga dan pemangku jabatan apakah konsep Hybrid ini dapat menjawab isu utama. Sehingga penelitian ini tidak tertutup kemungkinan terbuka untuk penelitian lanjutan. 


\section{Ucapan Terima Kasih}

Terima kasih kepada Direktur Direktorat Penelitian dan Pengabdian Masyarakat, Bapak Ir. Jap Tji Beng, Ph.D, Kepala Progam Magister Arsitektur Ibu Dr. Ir. Naniek Widayati M.T, dan juga Rukun Warga 015 Bapak Hartono Lioe, atas kerjasama yang baik hingga terlaksananya Pengabdian Kepada Masyarakat ini.

\section{REFERENSI}

Per, A. F., Mozas, J., Arpa, J. (2011). This is Hybrid. Spain: A + T Architecture Publishers. Ashiara, Y. (1971). Exterior Design in Architecture, USA: Van Nostrand Reinhold Inc.

Cassirer, E. (1965). An Essay on Man, USA: Yale University Press.

Dalyono, C. T. (Januari-April 2010). Pengaruh Media Massa dan Pengetahuan tentang Teknologi Informasi terhadap Pemanfaatan Teknologi Informasi dan Tingkat Modernitas Generasi Muda Kota Yogyakarta. Ilmu Komunikasi, 2010.

Mifflin, H. (2000). The American Heritage ${ }^{\circledR}$ Dictionary of the English Language, Fourth Edition, USA: Houghton Mifflin Company

Escudero, E. D. (2014). "Heidegger on Selfhood". American International Journal of Contemporary Research, 4(2), 6-17. February 2014. http://www.aijcrnet.com/journals/Vol_4_No_2_February_2014/2.pdf

Ikhwanuddin. (2005). Menggali Pemikiran Posmodernisme dalam Arsitektur. Yogyakarta: Gajah Mada University Press.

Jenckcs, C. (1978). Hybrid Language, USA: New Paradigm Architecture.

Jodido, P. (2005). Architecture Now. Koln: Taschen.

Kurokawa, K. (1994). The Philosophy Of Symbiosis. London: Academy Editions.

Salura, P (2013). Sebuah Kritik: Arsitektur Yang Membodohkan, Jakarta: Gakushudo Publishing. Meyer, E. D, (2013). Questioning Martin Heidegger, United Kingdom: University Press of America.

Nose, M. R. (2000). Japan Modern New Ideas for Contemporary Living. Japan: Tuttle Publishing.

Venture, R. (1966). Complexity and Contradiction in Architecture. New York: The Museum of Modern Art. 